\title{
Synthesis and evaluation of silver nanoparticles material for solid phase extraction of cobalt from water samples
}

\author{
Mostafa Khajeh • Esmael Sanchooli
}

Received: 3 August 2011/Accepted: 1 September 2011/Published online: 20 September 2011

(C) The Author(s) 2011. This article is published with open access at Springerlink.com

\begin{abstract}
In this study, a new solid phase extractor, nano-scale silver particles were synthesized. The silver nanoparticle-based solid phase extraction was used for separation and preconcentration of the trace amount of cobalt ion from various water samples prior to its determination by flame atomic absorption spectrometry. The effects of various parameters, including $\mathrm{pH}$, amount of complexing agent [1-(2-pyridylazo)-2-naphthol] (PAN), flow rates of solution and eluent, type and least amount of the eluent for elution of the cobalt from silver nanoparticles were studied and optimized. Under the optimum conditions, the detection limit of this procedure was $0.78 \mu \mathrm{g} \mathrm{L}^{-1}$, and the relative standard deviation (RSD\%) was 3.1\% $(n=10$, $\left.c=20 \mu \mathrm{g} \mathrm{L}^{-1}\right)$. This method was applied to the determination of cobalt in water samples.
\end{abstract}

Keywords Cobalt - Silver nanoparticle .

Solid phase extraction - Water samples

\section{Introduction}

The determination of heavy metals at trace levels in the environment is one of the most important targets of analytical chemists because of their roles in our life. Some trace metals, including cobalt are essential to human whose daily requirement is only a few milligrams. However, if ingested in high level, it can be harmful to human health. Therefore, the elemental composition is important to ensure the food quality. Furthermore, the metal content in

M. Khajeh $(\bowtie) \cdot$ E. Sanchooli

Department of Chemistry, University of Zabol,

P. O. Box 98615-538, Zabol, Iran

e-mail: m_khajeh@uoz.ac.ir water, sediment, plants and animals can also provide essential information on the levels of contamination in the environment (Baliza et al. 2009; Teixeira et al. 2001; Gil et al. 2008).

In the past decade, nano-scale solid materials have become very important due to their special properties (Zhai et al. 2006; Kalfa et al. 2009). Nano-materials possess a series of unique chemical and physical properties. One of their important properties is that most of the atoms that have high chemical activity and adsorption capacity to many element ions are on the surface of the nano-materials (Kalfa et al. 2009; Liu et al. 2005). The surface atoms are unsaturated, and, are subject to combination with other element ions by static electricity (Hang et al. 2002). Therefore, nanoparticles can adsorb element ions with good adsorption speed (Kalfa et al. 2009). Recently nanoparticles have been utilized as sorbent due to their improved intrinsic properties such as chemical activity and fine grain size compared with the classical substances such as normal scale titanium dioxide, alumina, etc. (Kalfa et al. 2009; Turker 2007; Lemos et al. 2008; Zhang et al. 2008). Nanoparticles were chemically modified by a reagent to obtain a new selective solid phase extractant for the preconcentration of metal ions (Kalfa et al. 2009).

The aim of this study was to develop a simple, fast and sensitive method for preconcentration and determination of cobalt in water samples using silver nanoparticles. The retention of Co-PAN complex on silver nanoparticles was based on the simple physical adsorption. The retention and elution conditions for preconcentration and determination by atomic absorption spectrometry (AAS) have been optimized. Finally, the developed method was verified by the determination of this element in water samples. 


\section{Materials and methods}

Apparatus

The measurements were performed with a Konik Won M300 (Barcelona, Spain) flame atomic absorption spectrometer (FAAS), equipped with a hollow cathode lamp and a deuterium background corrector, at respective wavelength using an air-acetylene flame. The instrumental parameters were those recommended by the manufacturer. The $\mathrm{pH}$ was determined with a model 630 Metrohm $\mathrm{pH}$ meter with combined glass-calomel electrode.

\section{Materials}

1-(2-pyridylazo)-2-naphthol (PAN) was obtained from Merck (Darmstadt, Germany). All acids, reagent grade $\mathrm{AgNO}_{3}$ and nitrate or chloride salts of other cations (all from Merck) were of the highest purity available. A stock solution of cobalt $\left(1,000 \mathrm{mg} \mathrm{L}^{-1}\right)$ was prepared by dissolving the proper amount of $\mathrm{Co}\left(\mathrm{NO}_{3}\right)_{2}$ in distilled water in a $10 \mathrm{~mL}$ flask. Dilute solutions were prepared by an appropriate dilution of the stock solution with double distilled water.

\section{Preparation of silver nanoparticles}

At $45^{\circ} \mathrm{C}, 90.0 \mathrm{mg}$ of $\mathrm{AgNO}_{3}$ was suspended in $500 \mathrm{~mL}$ deionized water and heated quickly to boiling under stirring. Immediately, after boiling, $10 \mathrm{~mL}$ of $1.0 \%$ sodium citrate solution was added rapidly, and then heating was reduced, but the solution was allowed to boil gently for 100 min with continuous stirring. The representative transmission electron microscopy (TEM) image of silver nanoparticle is shown in Fig. 1.

\section{Column preparation}

A plastic syringe with filter was used as a mini column and was filled with $500 \mathrm{mg}$ of dried synthesized silver nanoparticle. A filter was placed on the top to avoid disturbance of the adsorbent during sample passage.

\section{Extraction procedure}

The column was treated with $5 \mathrm{~mL}$ methanol and then with $5 \mathrm{~mL}$ of $0.5 \mathrm{~mol} \mathrm{~L}^{-1} \mathrm{HNO}_{3}$. Finally, the column was washed with deionized water until free from acid. A portion of aqueous sample solution $(100 \mathrm{~mL})$ containing $0.05 \mathrm{mg}$ cobalt was prepared, and then PAN was added to form the cobalt-PAN chelate. After that, the solutions were adjusted to the desired $\mathrm{pH}$ values and passed through the column. Subsequently, cobalt ions retained on the silver

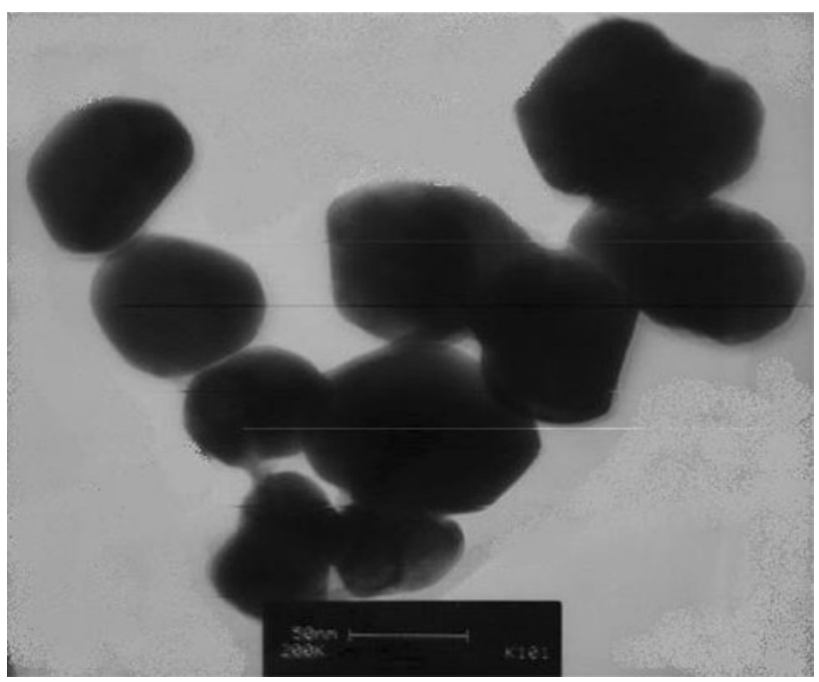

Fig. 1 TEM image of the silver nanoparticles

nanoparticles were eluted with desired volume and concentration of eluent. The eluent was analyzed for the determination of cobalt concentration by AAS.

\section{Results and discussion}

\section{Effect of $\mathrm{pH}$}

The $\mathrm{pH}$ value plays an important role for the quantitative extraction of the metal ions during the solid phase extraction method. In order to evaluate the effect of $\mathrm{pH}$ values on the extraction of cobalt, it is important to study the effect of $\mathrm{pH}$ in a wide range. The influence of $\mathrm{pH}$ on the extraction of cobalt ions ranging from 3 to 11 was investigated. As seen from Fig. 2, quantitative extraction (>97\%) was obtained in the $\mathrm{pH}$ range of $10-11$. Hence, the subsequent studies were performed with $\mathrm{pH} 11$.

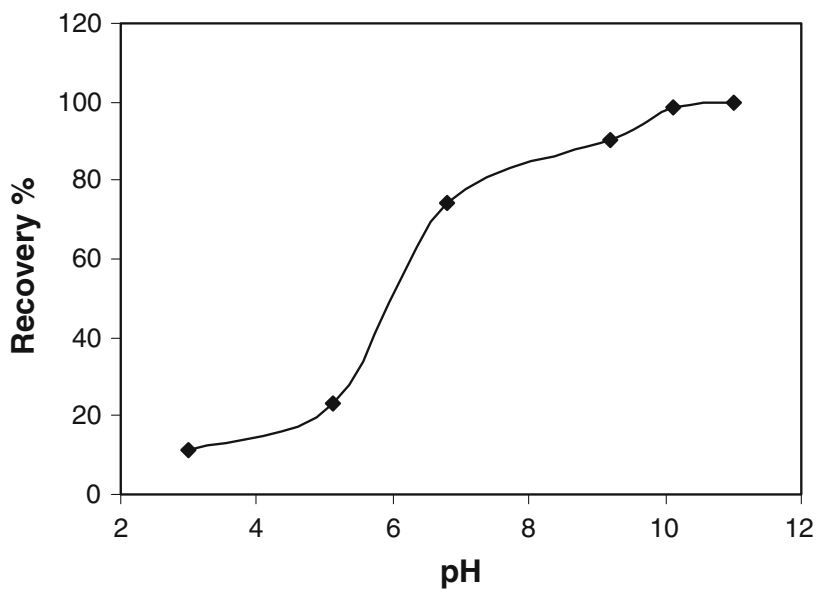

Fig. 2 Effect of $\mathrm{pH}$ on the recovery of cobalt ions 


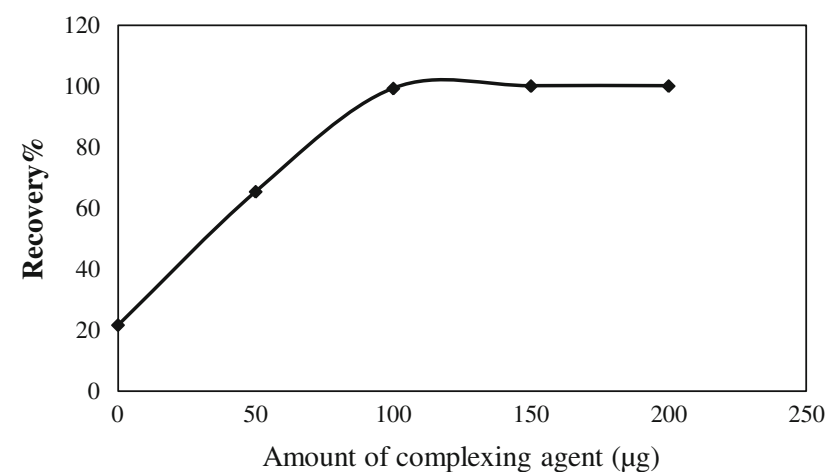

Fig. 3 Effect of amount of complexing agent on the recovery of cobalt ions

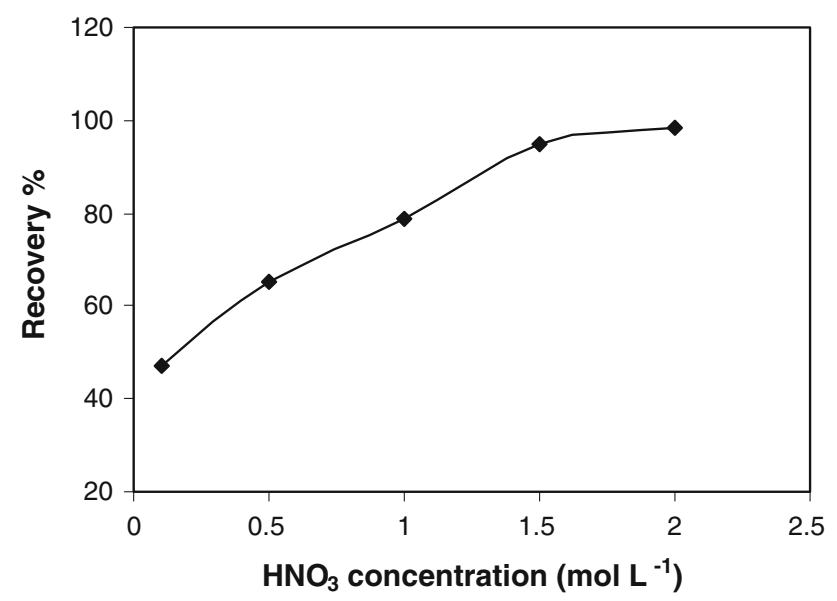

Fig. 4 Effect of $\mathrm{HNO}_{3}$ concentration on the recovery of cobalt ions

Effect of amount of complexing agent

The effect of the amount of PAN was checked in the preconcentration of cobalt ions. Different amounts of PAN ranging from 0.0 to $200 \mu \mathrm{g}$ in $50 \mathrm{~mL}$ were examined (Fig. 3) to investigate the optimum amount of complexing agent on the quantitative extraction of cobalt on silver nanoparticles. The results showed that the recovery was quantitative ( $>97 \%$ ) in the range of 100-200 $\mu \mathrm{g}$ of PAN; therefore, all studies were performed at $150 \mu \mathrm{g}$ of complexing agent.

\section{Effect of eluent concentration and volume}

Various concentrations of nitric acid were studied for the elution of cobalt from silver nanoparticles. The results obtained are shown in Fig. 4. It was found that $2 \mathrm{~mol} \mathrm{~L}^{-1}$ nitric acid was sufficient for quantitative elution $(>97 \%)$. The influence of eluent volume (1-7 mL) (Fig. 5) on the recovery was studied using $2 \mathrm{~mol} \mathrm{~L}^{-1}$ nitric acid. Quantitative recovery was obtained with $5 \mathrm{~mL}$ of this acid. Hence, $5 \mathrm{~mL}$ of $2 \mathrm{~mol} \mathrm{~L}^{-1}$ nitric acid was used as eluent in the subsequent experiments.

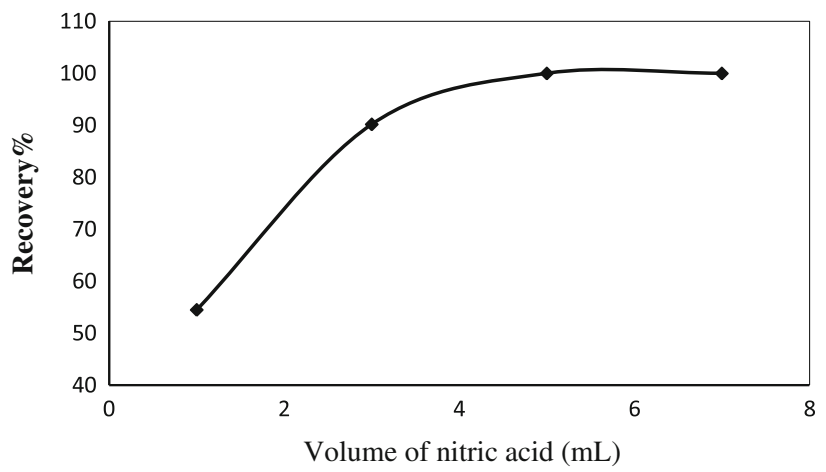

Fig. 5 Effect of volume of nitric acid on the recovery of cobalt ions

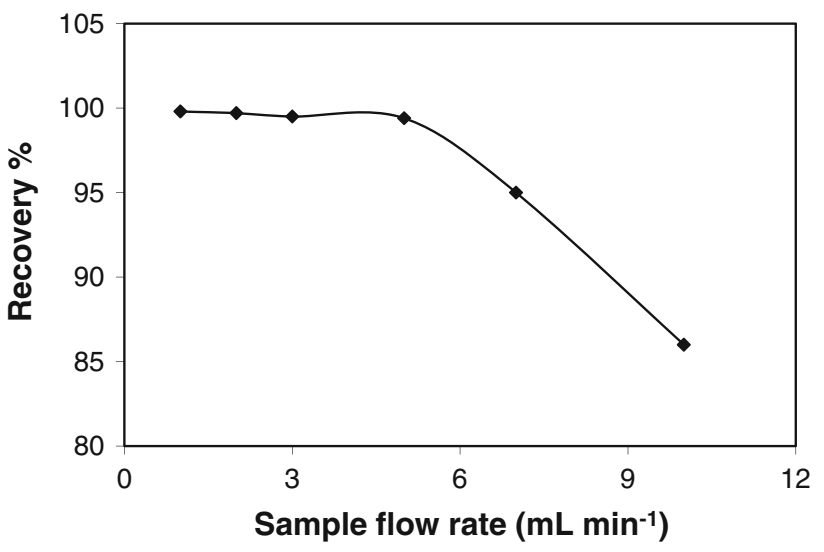

Fig. 6 Effect of sample flow rate on the recovery of cobalt ions

Effect of sample and eluent flow rate

The flow rate of the sample solution is a very important parameter because the retention of cobalt ions on the silver nanoparticles adsorbent depends on the flow rate of the sample solutions, while the flow of eluent solutions affects the recovery of the cobalt ions. In this study, different sample flow rates $\left(1.0-10.0 \mathrm{~mL} \mathrm{~min}^{-1}\right)$ were investigated. As shown in Fig. 6, the results indicated that the flow rate of the sample has a strong effect on the extraction of cobalt ions. The extraction of cobalt ions decreased with an increase in flow rate. The quantitative recovery was obtained with $1.0-5.0 \mathrm{~mL} \mathrm{~min}{ }^{-1}$. The flow rates of the eluent (1.0 to $5.0 \mathrm{~mL}$ ) (Fig. 7) were investigated. The quantitative recovery was obtained with 1.0 to $3.0 \mathrm{~mL} \mathrm{~min}{ }^{-1}$. Hence, flow rates of 5.0 and $3 \mathrm{~mL} \mathrm{~min}{ }^{-1}$ were selected as an optimum flow rate of the sample solution and eluent, respectively.

\section{Effect of coexisting ions}

The influence of common coexisting ions on the recovery of the cobalt ion on silver nanoparticles was also investigated. The experimental results are summarized in Table 1 . 


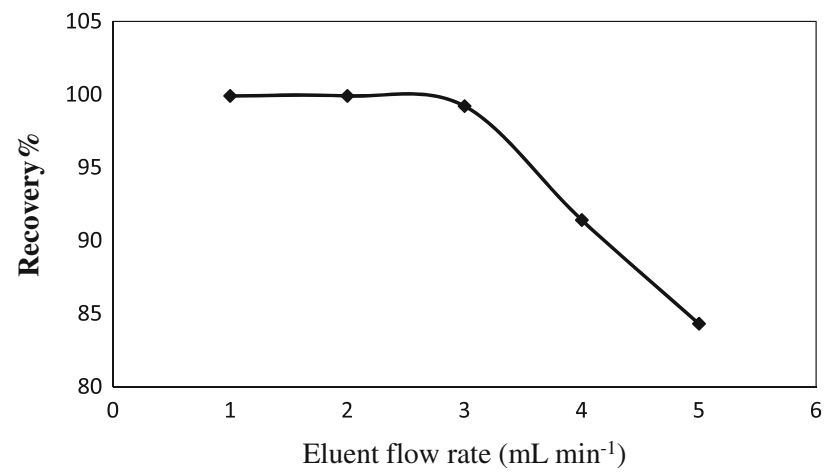

Fig. 7 Effect of eluent flow rate on the recovery of cobalt ions

Table 1 Extraction of cobalt from binary mixture

\begin{tabular}{lll}
\hline Foreign ion & $\begin{array}{l}\text { [nterfering ion]/ } \\
\text { [cobalt ion] }\end{array}$ & $\begin{array}{l}\text { Recovery of } \\
\text { cobalt }(\%)\end{array}$ \\
\hline $\mathrm{Li}^{+}$ & 1,000 & 100.0 \\
$\mathrm{Na}^{+}$ & 1,000 & 100.0 \\
$\mathrm{~K}^{+}$ & 1,000 & 100.0 \\
$\mathrm{Mg}^{2+}$ & 1,000 & 100.0 \\
$\mathrm{Ca}^{2+}$ & 1,000 & 100.0 \\
$\mathrm{Sr}^{2+}$ & 1,000 & 100.0 \\
$\mathrm{Ba}^{2+}$ & 1,000 & 100.0 \\
$\mathrm{Cu}^{2+}$ & 150 & 97.3 \\
$\mathrm{Zn}^{2+}$ & 150 & 98.5 \\
$\mathrm{Ni}^{2+}$ & 150 & 98.1 \\
$\mathrm{~Pb}^{2+}$ & 150 & 97.0 \\
\hline
\end{tabular}

The results show that the percent extraction of cobalt was almost quantitative $(>97 \%)$ in the presence of diverse ions. It was observed that the presence of ions do not interfere under the experimental conditions applied.

\section{Analytical figures of merit}

Under the optimum conditions described, the calibration curve was linear over a concentration range of 10.0$50.0 \mu \mathrm{g} \mathrm{L}^{-1}$. The least square equation at above dynamic linear range was as follows:

$A=0.0012 C\left(\mu \mathrm{g} \mathrm{L}^{-1}\right)+0.001 \quad\left(r^{2}=0.992\right)$

The limit of detection (LOD) of this method for the determination of cobalt was studied under the optimal experimental conditions. The LOD obtained from $C_{\mathrm{LOD}}=3\left(S_{\mathrm{d}}\right)_{\text {blank }} / m$ was $0.78 \mu \mathrm{g} \mathrm{L}^{-1}$, where $S_{\mathrm{d}}$ is the standard deviation of ten consecutive measurements of the blank and $m$ is the slope of the calibration curve. The experimental enhancement factor calculated as the ratio of the slopes of the calibration graphs with and without preconcentration was 50.0. The relative standard deviation (RSD\%) of the ten replicate determinations was $<3.1 \%$
Table 2 Determination of cobalt in water samples $(N=3)$

\begin{tabular}{|c|c|c|c|}
\hline \multirow[t]{2}{*}{ Samples } & \multicolumn{2}{|c|}{ Cobalt content $\left(\mu \mathrm{g} \mathrm{L}^{-1}\right)$} & \multirow[t]{2}{*}{ Recovery (\%) } \\
\hline & Added & Found $( \pm \mathrm{RSD})$ & \\
\hline \multirow[t]{2}{*}{ Tap water } & - & $2.8 \pm 0.8$ & - \\
\hline & 50.0 & $52.75 \pm 0.7$ & 99.9 \\
\hline \multirow[t]{2}{*}{ River water } & - & $3.1 \pm 1.2$ & - \\
\hline & 50.0 & $52.95 \pm 1.0$ & 99.7 \\
\hline \multirow[t]{2}{*}{ Sea water } & - & $3.6 \pm 2.8$ & - \\
\hline & 50.0 & $52.8 \pm 3.0$ & 98.4 \\
\hline \multirow[t]{2}{*}{ Saline serum ${ }^{a}$} & - & - & - \\
\hline & 50.0 & $48.9 \pm 2.3$ & 97.8 \\
\hline
\end{tabular}

${ }^{a}$ Produced by Daru Paksh Company, Iran

which indicated this method has a good precision for the analysis of trace cobalt in the sample solution.

The LOD, RSD\% and enrichment factor of this method were compared with other procedure. The LOD, RSD\% and enrichment factor of this method were $0.78 \mu \mathrm{g} \mathrm{L}^{-1}$, $3.1 \%$ and 50 , respectively, whereas, in previously published paper the LOD, RSD\% and enrichment factor were $0.9 \mu \mathrm{g} \mathrm{L}^{-1}, 5.8 \%$ and 16 , respectively (Baliza et al. 2009).

Analysis of real samples

This method was applied to the cobalt determination in water samples. In addition, the recovery experiments of various amounts of cobalt were carried out, and the results are shown in Table 2.

\section{Conclusion}

In this work, a new solid phase extractor, silver nanoparticles were synthesized and used for the preconcentration of trace amount of cobalt ions from water samples. As the diameter of the particle decreases to the nanometer scale, large external surface area becomes available for surface modifications, and increases the rate of reaction. Silver nanoparticles as a new solid phase extractor provide a simple, selective, fast and precise procedure for the separation and preconcentration of cobalt.

Open Access This article is distributed under the terms of the Creative Commons Attribution License which permits any use, distribution and reproduction in any medium, provided the original author(s) and source are credited.

\section{References}

Baliza PX, Teixeira LSG, Lemos VA (2009) A procedure for determination of cobalt in water samples after dispersive liquidliquid microextraction. Microchem J 93:220-224 
Gil RA, Gasquez JA, Olsina R, Martinez LD, Cerutti S (2008) Cloud point extraction for cobalt preconcentration with on-line phase separation in a knotted reactor followed by ETAAS determination in drinking waters. Talanta 76:669-673

Hang Y, Quin Y, Jiang Z, Hu B (2002) Direct analysis of trace rare earth elements by fluorination assisted ETV-ICP-AES with slurry sampling through nano-sized $\mathrm{TiO}_{2}$ separation/preconcentration. Anal Sci 18:843-846

Kalfa OM, Yalcinkaya O, Turker AR (2009) Synthesis of nano $\mathrm{B}_{2} \mathrm{O}_{3} /$ $\mathrm{TiO}_{2}$ composite material as a new solid phase extractor and its application to preconcentration and separation of cadmium. J Hazard Mater 166:455-461

Lemos VA, Teixeira LSG, Bezerra MA, Costa ACS, Castro JT, Cardoso LAM, Jesus DS, Santos ES, Baliza PX, Santos LN (2008) New materials for solid-phase extraction of trace elements. Appl Spectrosc Rev 43:303-334
Liu Y, Liang P, Guo L (2005) Nanometer titanium dioxide immobilized on silica gel as sorbent for preconcentration of metal ions prior to their determination by inductively coupled plasma atomic emission spectrometry. Talanta 68:25-30

Teixeira LSG, Costa ACS, Assis JCR, Ferreira SLC, Korn M (2001) Solid phase spectrophotometry for the determination of cobalt in pharmaceutical preparations. Microchim Acta 137:29-33

Turker AR (2007) New sorbents for solid-phase extraction for metal enrichment. Clean 35:548-557

Zhai Y, Chang X, Cui Y, Lian N, Lai S, Zhen H, He Q (2006) Selective determination of trace mercury(II) after preconcentration with 4-(2-pyridylazo) resorcinol modified nanometer-sized $\mathrm{SiO}_{2}$ particles from sample solutions. Microchim Acta 154:253-259

Zhang L, Huang T, Zhang M, Guo X, Yuan Z (2008) Studies on the capability and behavior of adsorption of thallium on nano- $\mathrm{Al}_{2} \mathrm{O}_{3}$. J Hazard Mater 157:352-357 